CHILDREN'S KNOWLEDGE OF ONLINE SAFETY/DANGER

To appear in Journal of Children and Media

Running head: CHILDREN'S KNOWLEDGE OF ONLINE SAFETY/DANGER

Subjective versus objective knowledge of online safety/dangers as predictors of children's perceived online safety and attitudes towards e-safety education in the United Kingdom

Peter J. R. Macaulay ${ }^{1,2 *}$, Michael J. Boulton ${ }^{3}$, Lucy R. Betts ${ }^{2}$, Louise Boulton ${ }^{3}$, Eleonora Camerone $^{3}$, James Down ${ }^{3}$, Joanna Hughes ${ }^{3}$, Chloe Kirkbride ${ }^{3}$ \& Rachel Kirkham ${ }^{3}$ Staffordshire University ${ }^{1}$, Nottingham Trent University ${ }^{2}$, and University of Chester ${ }^{3}$

*Corresponding author

${ }^{1}$ Department of Psychology, Staffordshire University, Science Centre, Leek Road, Stoke on Trent, ST4 2DF, England.

Tel: 01782294896

Email: Peter.Macaulay@staffs.ac.uk 


\section{Biographical author notes}

Peter J. R. Macaulay is a Lecturer in Psychology at Staffordshire University, UK. His main research interests are in the area of social development, focusing specifically on teacher's perceptions towards cyberbullying, children's bystander behaviour in the online/offline domain, and children's knowledge of online risks and safety.

Michael J. Boulton is an Emeritus Professor of Psychology at the University of Chester, UK. He has research interests in bullying related issues, is recognised as an international expert on bullying among school pupils and has published numerous papers on the topic over 25 years. Lucy R. Betts is an Associate Professor in Psychology at Nottingham Trent University, UK. Her main research interests are in the area of social development, focusing specifically on children's experiences of bullying and cyber bullying, peer relationships, social networks, and friendships.

Louise Boulton has been conducting research on well-being, bullying, and behaviour related issues for more than 10 years.

Eleonora Camerone is a graduate from the University of Chester, UK

James Down is an independent trainer and consultant specialising in child internet safety and serves as a school governor with responsibilities for safeguarding and child protection. James is also a graduate member of the British Psychological Society, with research interests in cyber bullying and risky online behaviours by young people

Joanna Hughes is a graduate from the University of Chester, UK

Chloe Kirkbride is a graduate from the University of Chester, UK

Rachel Kirkham is a graduate from the University of Chester, UK 


\title{
Subjective versus objective knowledge of online safety/dangers as predictors of children's perceived online safety and attitudes towards e-safety education in the United
}

\section{Kingdom}

\begin{abstract}
Children are spending increasing amounts of time online prompting practitioners and parents to raise concerns about their online safety. However, the impact of children's subjective versus objective knowledge on their perceived online safety and attitudes towards e-safety education remain unclear. Questionnaires were used to assess children's $(\mathrm{N}=329$, aged 8-11 years) perceived online safety, subjective and objective knowledge of online safety/dangers, and attitudes to e-safety education. While participants generally reported feeling safe online and perceived that they had a good awareness of online dangers and how to avoid them (subjective knowledge), they tended to be poor at articulating for themselves exactly what those dangers were and how they personally could elude them (objective knowledge). This was especially true of boys and younger children. Moreover, only subjective knowledge of online safety/dangers significantly predicted perceived online safety. Together, these findings suggest that some children may think that they know how to stay safe online but lack - or at least be unable to articulate - objective knowledge that could actually keep them safe. Consequently, there is a need to assess children's objective knowledge of online safety/dangers and to provide appropriate education for children who currently lack it.
\end{abstract}

Keywords: online safety; online dangers; e-safety; internet; children 


\section{Introduction}

With the emergence of digital technology, children are spending more time online with potential negative and positive consequences (Livingstone, Haddon, Görzig, \& Ólafsson, 2011). Recent figures suggest that $94 \%$ of 8 to 11 -year-olds in the UK spend approximately 13 hours per week online (Ofcom, 2017). The growth in children's digital technology use over recent years has prompted concern among researchers and practitioners about the associated risks of using digital technology which may lead to adverse emotional and social consequences (Livingstone \& Smith, 2014). These online risks include: contact with strangers, sharing personal information, cyberbullying, hurtful online material, and viruses (Livingstone et al., 2011; Livingstone, Kirwil, Ponte, \& Staksrud, 2014; Livingstone, \& Smith, 2014). While not all potential risks result in actual harm (Livingstone, 2013), there is still a need to understand how young people can be helped to stay safe online (Livingstone et al., 2017) and to gain the considerable educational, social, and recreational benefits that the internet affords (Finkelhor, 2014; Madden, Lenhart, Duggan, Cortesi, \& Gasser, 2013).

Risk taking behaviours are those behaviours that balance the chance of a negative outcome such as harm with the chance of a positive outcome (Tieskens, Buil, Koot, Krabbendam, \& van Lier, 2018). Focusing on risk taking in elementary school children, Morrongiello and Lasenby-Lessard (2007) developed a theoretical model that recognised risk taking as a multi-determined outcome influenced by the child, parents, and social-situational factors. Child individual characteristics included: age, sex, behavioural attributes, experience with the activity, personal motivations and values, and temperament. Parent factors were socialisation processes, teaching practices, parent modelling, parenting style and attributes, and sibling effects. Social-situational factors are oral/persuasion influences, observational influences, and situation driven motivations. Together, these factors interact with macro-level influences such as the neighbourhood, economics, and culture to predict risk taking. While 
researchers have typically explored children's risk taking in outdoor play (Morrongiello, McArthur, Kane, \& Fleury, 2013), safety practices (Morrongiello et al., 2008), and injury experiences (Morrongiello et al., 2010), children's increasing use of online spaces (Ofcom, 2017) means that it is timely to explore online risks.

A large-scale international survey conducted with 9 to 16 -year-olds across 25 countries stated that more than half of the 25,142 reported experiencing one online risk, approximately $30 \%$ two online risks, and approximately $15 \%$ three or more online risks (Livingstone, Kirwil et al., 2014). Consequently, given children's propensity to be exposed to online risks, research is needed to establish how safe children feel when using the internet, and strategies they use to help them stay safe. Although some evidence suggests children recognise the opportunities the internet affords and the need to stay safe online (Betts \& Spenser, 2017) and while using technology (Bond, 2013), other researchers argue children's knowledge about how to stay safe online is inadequate (Cranmer, 2013). For example, Cranmer reported that although children discussed that they should use privacy controls to stay safe online they did not know how to use them effectively and, as a result, experienced sexually abusive comments which caused distress. Consequently, additional research is needed to explore children's knowledge of online dangers, and more importantly, how to stay safe while using the internet. The present study addressed these issues.

Knowledge involves both 'subjective' and 'objective' components (Brucks, 1986). Subjective knowledge pertains to what individuals perceive that they know in a given context whereas objective knowledge is what individuals actually know in a given context. Han (2019) notes that although it would be expected that these two types of knowledge would be strongly correlated, research has frequently reported small to modest correlations. Therefore, differences can emerge between 'objective' and 'subjective' knowledge if children do not correctly reflect on their perceived and actual knowledge (i.e., how little or how much they 
really know) which can impact on their risk-taking behaviours. Similar discrepancies have been identified in adolescents' knowledge of sexual health (Kouta \& Tolma, 2008) and large discrepancies between perceived and actual knowledge of gambling were associated with elevated problem gambling (Delfabbro, Lahn, \& Grabosky, 2006). This is the first known study to apply and test these concepts in the context of online safety/dangers. In the context of the current study, 'subjective' knowledge denotes children's perceived feeling that they know about online dangers/safety, whereas 'objective' knowledge reflects children's actual knowledge of online dangers/safety. As such, a low level of 'subjective' knowledge of online dangers/safety would indicate a perception of knowing little about online dangers/safety, whereas a higher level would indicate a greater perception of knowledge in this area. Therefore, the current study examined to what extent children: (i) believe, and (ii) show objective evidence, that they know of the risks of using the internet and what to do to stay safe online.

One issue, aligned to subjective and objective knowledge of online risks, that has received scant attention is online perceived safety. Online perceived safety reflects how safe young people think they are online. Perceived safety has been shown to be closely related to wellbeing in diverse offline contexts. Young people who feel unsafe in the school classroom and playground (Boulton, Woodmansey, \& Williams et al, 2012) and wider neighbourhood (Dallago, Perkins, \& Santinello, 2009) show reduced wellbeing. Moreover, feeling unsafe in offline contexts can be associated with disrupted cognitive functioning (Boulton et al., 2012) and behavioural change (Davison \& Lawson, 2006). It is likely that there are similar findings relating to safety behaviour for both offline and online settings because previous research has highlighted substantial similarities between offline and online social behaviour (Ivcevic \& Ambady, 2013). It follows that if young people are to benefit most from using the internet, they should feel safe while online. There is no known study that has attempted to quantify 
how safe children feel on the internet with a psychometrically sound instrument. Some prior studies have used single item measures of safety (Dallago et al., 2009) but others have cautioned against this practice because such single-item measures "are presumed to have unacceptably low reliability" (Wanous, Reichers, \& Hudy, 1997, p247), calling instead for multi-item measures that allow tests of psychometric properties (Boulton et al., 2009). Therefore, the current study addressed this issue by using a multi-item measure to assess children's online perceived safety.

While it is important that young people do feel safe online, these feelings would need to be based on sound knowledge of cyber risks and how to avoid them if children are to actually remain safe. Hence, there is also value to be had in studying what affects young people's feelings of internet (un)safety, but again few studies have been reported. Research has shown that many young people are aware of some, indeed many, of the risks and dangers associated with using the internet and how to stay safe while using it (Livingstone, Haddon, Vincent, Mascheroni \& Ólafsson, 2014), but the extent to which it can predict perceived safety has not been assessed. No prior study has solicited from young people both their 'objective' and 'subjective' knowledge about internet risks and safety and tested their combined and unique contribution to the prediction of perceived safety. That such predictive associations might exist is suggested by theories of the origins of fear in offline domains, especially fear of crime, which highlight the precipitating role of knowledge of potential risks and how to avoid them (Hinkle, 2015). According to this theoretical framework, the more children know about online risks/how to stay safe, the more they would tend to feel safe online. This 'knowledge predicts perceived safety' hypothesis has not been tested to date. Any test of it would need to recognize that the method(s) used to measure knowledge is/are important. Research on young people's (un)safety has largely used quantitative methodologies, predominantly across adolescent populations, with younger children often 
under-researched (Donoso, Ólafsson, \& Broddason, 2009). However, the methods used to generate such data exert a big influence on the quality of the data (see Method).

Equipping young people with knowledge of how to stay safe online via formal education is widely regarded as appropriate (Sharples, Graber, Harrison, \& Logan, 2009). This runs counter to the 'myth of the digital native', which implies that young people naturally or automatically acquire digital literacy (Helsper \& Eynon, 2010). While the availability to be connected online continues to grow, young children need to acquire digital literacy if they are to remain safe online. Although children may automatically acquire these skills, they need to be aware of the different skills, activities and dangers/safety associated with the internet in order to actually remain safe online (Helsper \& Eynon, 2010; Helsper \& Eynon, 2013; Lee \& Chae, 2012). The knowledge, attitude, practice model (Lbrahim, 1995) suggests that knowledge predicts attitudes. In the context of Lbrahim's model, attitudes are the result of a reaction to a particular situation that is guided by an individual's prior knowledge. Focusing on explicit attitude evaluations, the more recent associative-propositional evaluation model (Gawronski \& Bodenhausen, 2011) argues that explicit evaluations for a particular topic are a behavioural outcome derived from propositional processes. Propositional processes are the validation of an individual's information held in their memory relating to the particular attitude in question. Therefore, in the context of the current study, an individual's attitude towards e-safety would be based on the validity of the prior knowledge in their memory in the form of subjective and objective knowledge of online risks/safety. There is no known study that has attempted to explore if attitudes towards e-safety education could be predicted from subjective and objective knowledge, and so this study will offer a unique insight on these relations. As such, the study will examaine to what extent children: (i) feel (un)safe on the internet, and (ii) hold positive attitudes towards formal e-safety education. The study will also examine to what extent objective and subjective knowledge about online risks/safety 
predict (i) levels of perceived safety online and (ii) attitudes towards formal e-safety education?

Currently, little is also known about sex differences in online perceived safety, but some indirect evidence suggests they might exist. Boys are known to be less risk-averse than girls generally (Fogel \& Nehmad, 2009; Junger-Tas \& Ribeaud, 2004) and boys have been found to engage in online behaviour that exposes them to more inappropriate and potentially distressing content (Baumgartner, Valkenburg, \& Peter, 2010; Oksanen et al., 2016; Sasson \& Mesch, 2014). Boys also spend more time online and engage in riskier online communication behaviour, leaving them more exposed to risks (Leung \& Lee, 2012; Sasson \& Mesch, 2014). For example, research exploring adolescent risk-taking in the online domain found boys were more likely to engage in risk-taking behaviour, attributed to limited social interaction in the physical world (Stamoulis \& Farley, 2010). In addition, it was females compared to males that were less likely to be exposed to online dangers (Livingstone \& Helsper, 2007). Such experiences might leave boys feeling less safe than girls online. On the other hand, the finding that boys take more risks online might suggest they feel safer than girls in that context. Sex differences in subjective knowledge about internet risks and safety have been reported, with boys claiming higher levels (Livingstone, Haddon et al., 2014). From a theoretical perspective, Gustafson (1998) argues that gender differences in risk perception arise because of the interaction between practice and gender ideology (an expression of gender structures, logic of segregation and hierarchy). Consequently, it is important to examine if sex moderates any associations between subjective/objective knowledge about internet risks/how to avoid them and perceived safety.

Most extant research in this area has predominantly investigated older children's perspectives regarding online dangers and internet safety (typically 11 years old or above). There is a need to explore younger children's views in this area (typically 10 years old or 
lower), as the online dangers exposed to them are likely to be different to their older peers, and so children's age could play a role in their knowledge of online dangers and how to stay safe online. For example, younger children are less likely to be exposed to online risks compared to older children, as they engage in less social interaction and activities in the online domain (Chaudron et al., 2015; Livingstone \& Helsper, 2007). This is because younger children will have restricted access to online activities, whereas older children engage in more online interactions (i.e., through gaming, networking sites) that expose them to more online dangers (Chaudron et al., 2015; Ofcom, 2017). In addition, younger children are accessing the internet to watch videos and to complete homework (Holloway, Green, \& Livingstone, 2013), showing a modest understanding of what 'online' actually means (Chaudron et al., 2015). This reduced awareness among younger children when using the internet could impact on their perceived safety. Moreover, research has reported a linear developmental trajectory of risk taking from childhood to adolescence (van den Bos \& Hertwig, 2017), suggesting that while knowledge may be greater in older children, perceptions of risk may be different across childhood. This could suggest there may be a difference in younger and older children's knowledge of online dangers/safety and, as such, age was explored as a potential moderator in the relationship between children's knowledge of online dangers/safety.

Studying the aforementioned variables - perceived online safety, subjective/objective knowledge of online risks and how to avoid them, and openness to 'formal' e-safety education - can help inform practical efforts to ensure that children gain the most benefit with least risk and actual harm from using the internet. Therefore, the current study addressed the following questions:

1. To what extent do children: (i) believe, and (ii) show objective evidence, that they know of the risks of using the internet and what to do to stay safe online 
2. To what extent do children: (i) feel (un)safe on the internet, and (ii) hold positive attitudes towards formal e-safety education?

3. To what extent can objective and subjective knowledge about online risks/safety relate to (i) levels of perceived safety online and (ii) attitudes towards formal e-safety education?

4. What are the sex/age differences, if any, in all of the above?

\section{Method}

\section{Participants and Procedure}

The sample consisted of 329 (167 girls and 162 boys) children from Year 4 ( $\mathrm{n}=175$, 89 girls and 86 boys $)$ and Year $6(n=154,78$ girls and 76 boys), aged between $8-11$ years, drawn from five primary schools in the UK. As stated in the Introduction, 8-11-year-old children were selected for this study as younger children are spending more time online (Livingstone et al., 2011; Livingstone, Haddon et al., 2014; Ofcom, 2017), and their perspectives are largely under-reported and yet to be established. It should be noted that Year 5 pupils were not recruited to participate in the current study in order to truly reflect and examine younger and older children's knowledge of online safety/danger. By excluding an academic year level, age differences in the examined relations between younger (Year 4) and older (Year 6) would be more apparent and provide a better insight on their knowledge of online safety/danger. Piaget's work on understanding child development continues to help inform and influence research today. Developmental differences exist between Year 4 and 6 children which also may explain any age differences in knowledge of online safety. Children aged 8-11 start to develop and recognise multiple perspectives as they interact with their peers. As such, children recognise social constructs and rules in their environment (Thorton, 2008). These multiple perspectives and awareness of social rules may influence how children 
interact online, and their knowledge of online safety/dangers. In addition, Piaget's theory on concrete operational reasoning would explain that children start to develop reversible mental operations where they can start to explain and understand logical relations. As such, children are expected to have greater executive control over their behaviour as they get older (Thorton, 2008). Therefore, it is expected older children (e.g., 10-11-year olds) would be more autonomous and rigorous in how they behave online, whereas younger children (e.g., 89-year olds) are more likely to be disorganised and dependant on others. This could explain potential differences in children's knowledge of online safety/dangers. The study was conducted between 2015-2016.

The schools were contacted across the UK, in the Midlands and North West of England. The Midlands is a region in central England. The North West is a northern region of England. These regions of England were chosen based on the author(s) convenience to recruit schools in these areas. The participating schools were all typical state public schools in both urban and rural areas that included children from a range of socio-economic backgrounds. The schools were selected based on the criteria they were (a) state public schools, (b) classified as a primary school (typical age range 3-11 years), and (c) a mixed sex school. Initially, approximately 10 schools were contacted to participate in the current study, and 5 schools consented to take part. Consent was gained from the headteacher, parents/guardians, and the pupils completing the survey. Data were collected on a whole class basis, after informed consent was obtained from the school staff, parents and the children. At the school's request, ethnicity data were not collected. Initially, once the schools agreed to take part in the project, a group discussion with teachers at each school was conducted during a staff meeting/after the school day. The teachers offered their expert/experienced views and perspectives on the measures to make sure the wording was understandable for children aged 8-11 years. Each class had approximately 15-20 children. The session was conducted to align 
with the schools e-safety week to avoid conflicting with other National Curriculum requirements. The author(s) provided details on the survey and the children were reminded that they do not have to take part, and if preferred, could read/complete an e-safety worksheet provided by the school.

A number of steps were taken to encourage honest and considered responses, especially important for the measure of 'objective' knowledge, and to also meet prior methodological/ethical recommendations researching children (Görzig, 2012; Livingstone, Kirwil et al., 2014). It was emphasised that it was not a test because there were no right or wrong answers, and that each person's individual response would be valued. Participants were asked not to put their name on the questionnaire, informed that their individual responses could not be identified, and it was reiterated that their responses would form an overview from a large number of young people. The researcher read out each item in turn, and participants were invited to ask questions if they were not sure about the wording. It was reiterated that spelling/grammar were not important. Sufficient time was given for them to think about their answer and make their response. The survey took approximately 10-15 minutes to complete, which was administered through paper and pen. Children were seated so that they could not see each other's responses. Once completed, the children posted their survey in an anonymous box to ensure privacy and encourage honest responses (Görzig, 2012). As such, steps were taken to increase the quality of the data in order for the children to complete the questionnaire accurately, allowing younger and older children to complete the survey with a good understanding of the questions and time to accurately fill them in (Borgers, De Leeuw, \& Hox, 2000; Lenske \& Helmke, 2015; Riley, 2004). As the present study involved developing new measures to assess the constructs, in line with Berchtold's (2016) recommendation test-retest reliability was examined to provide additional psychometric information for the scales. In order to provide test-retest reliability data, and in 
line with Shoukri, Asyali, and Donner's (2004), a sub-set of the sample $(\mathrm{n}=72)$ was asked to complete the questionnaire again two weeks after the first administration. To select this subsample, a random selection of children from each school were selected to complete the survey. The authors re-visited the school(s) to administer the survey following the same procedures outlined above.

\section{Measures}

Measuring children's internet (un)safety is one that comes with difficulty, with research highlighting the role of wording within questions influencing children's responses (Ponte, Simões, \& Jorge, 2013; Livingstone, Kirwil et al., 2014). Most of this work has used closed format questions or items (e.g., "Does doing X online put you in danger?") that could result in response acquiescence (e.g., participants default to a "Yes" response) and may have overestimated their 'knowledge' (Lavrakas, 2008; Livingstone, 2013). We regard this as a measure of subjective knowledge (i.e., they say that they know something). On the other hand, open questions are more challenging because they require young people to articulate with no prompting sometimes quite sophisticated ideas that they may not have even thought about before. It is not surprising that young people tend to give brief (if any) answers to open questions (Waterman \& Blades, 2000). So, while open questions run the risk of underestimating children's knowledge, they remain the best tool of quantifying their objective knowledge (i.e., they show evidence that children know something). Clearly, both open and closed questioning have different virtues/limitations.

Perceived online safety. This was measured with five items, 'I don't feel in danger when I am on the internet' (r), 'I can relax and enjoy it when I am on the internet' (r), 'I feel safe when I am on the internet' (r), 'I feel scared when I am on the internet', and 'Bad things can happen to me when I am on the internet'. Each item had a 4-point response option scale anchored by Agree a lot/Disagree a lot, scored 1-4 or 4-1 for positively worded items 
(denoted by 'r' above). Cronbach's alpha was .71. On an exploratory factor analysis using principal axis factoring, Kaiser's criterion and a scree plot converged to indicate a single factor with an eigenvalue of 2.38 that accounted for $47.7 \%$ of the variance. Hence, an overall mean score was computed, with high scores reflecting higher feelings of safety, $M=2.96$ ( $S D$ $=.62)$. Test-retest reliability was $r(n=72)=.72, p<.001$.

Subjective knowledge of online safety/dangers. Following other researchers who have measured self-reported online competence/confidence (Livingstone, Haddon et al., 2014), this was assessed with two items, 'I know what to do to stay safe on the internet' and 'I know what things could put me in danger or upset me on the internet'. Each item had a 4-point response option scale anchored by Disagree a lot/Agree a lot, scored 1-4. Responses were significantly correlated $(r=.46, p<.001)$ and so an average was computed, with high scores reflecting greater subjective knowledge, $M=3.44(S D=.72)$. Test-retest reliability was $r(n$ $=76)=.47, p<.001$.

Objective knowledge of online safety/dangers. This was assessed with two open questions, 'What things might put someone in danger of harm, or make them feel upset, when they use the internet?' and 'What things can you do to stay safe from harm or getting upset on the internet?' To achieve high face validity, these open questions on objective knowledge of online safety/dangers were formulated in collaboration with teachers. Children were encouraged to write down as many relevant things as they could. Because children face challenges trying to answer open questions (Waterman \& Blades, 2000), steps were taken to make it as easy as possible for them to give their well-considered responses, as noted in the Procedure section, above. The open questions were coded by five researchers using the coding scheme developed, which consisted of a concrete definition and example quotes from the data to provide consistency (Creswell \& Poth, 2016), as shown in Table 1. Following data collection, researchers initially read through the responses and arrived at a coding scheme of 
the most common responses for online dangers/safety. The coding frame was then reviewed and revised to meet prior research recommendations on children's online risks and how to stay safe online (Boulton et al., 2016; Chaudron et al., 2015; Livingstone et al., 2011). To receive an expert opinion, the coding frame was assessed by one of the authors who had prior experience in the police force being responsible for promoting e-safety issues and who is now currently responsible for child protection and advising safeguarding boards/committees. As shown in Table 1, six categories/themes were identified: People online pretending to be somebody else; Being in contact with people we do not know; Sharing personal information/personal photographs or videos; cyberbullying; Inappropriate and/or distressing content; and computer viruses. The researchers coded the responses using the coding scheme and tallied the number of times any of the specific categories were given by each participant. The latter represented each participants' score for objective knowledge of online safety/dangers. The score for objective knowledge of online safety/danger was calculated by combining the score of the two open questions for each participant, $\mathrm{M}=2.21$ ( $\mathrm{SD}=1.16$ ). This suggests participants could only articulate on average about two distinct responses regarding their knowledge of online safety/dangers. The coding frame was developed and used to look at the profile of response, as children use a range in how they interact online. Inter-coder reliability was high, 93\%. This method is recognised as an accurate measurement (Gwet, 2014), and the use of a coding system has been used in prior research to establish an 'overall' score for the desired variable (Boulton et al., 2016; Macaulay, Boulton, \& Betts, 2018; Saldaña, 2015). Krippendorff's alpha ( $\alpha$ ) was calculated to assess the reliability of the overall coding scheme. Inter-rater reliability was found to be high and satisfactory, with $\alpha$ $=.819(95 \% \mathrm{CI} .794-.842)$, exceeding recommendations of $\alpha=\geq .8$ (Hayes, $\&$ Krippendorff, 2007; Krippendorff, 2004). Test-retest reliability was found to be moderate, $r$ $(n=75)=.37, p<.001$. 
Attitudes to e-safety education. This was assessed with four items, 'I think it is important that young people are taught how to stay safe on the internet', 'Teaching young people how to stay safe on the internet is a good idea', 'More young people should learn about how to stay safe on the internet at school' and 'I would like to learn more about how to stay safe on the internet at school'. Each had a 4-point response option scale anchored by Agree a lot/Disagree a lot, scored 4-1. These items were constructed for the current study, and as such, test-retest reliability was considered to provide psychometric properties for these items (Berchtold, 2016). Cronbach's alpha was .62, acceptable for a short scale (Streiner, 2003). On an exploratory factor analysis using principal axis factoring, Kaiser's criterion and a scree plot converged to indicate a single factor with an eigenvalue of 2.08 that accounted for $52.0 \%$ of the variance. Hence, an overall mean score was computed, with high scores reflecting more positive attitudes towards e-safety, $M=3.69(S D=.44)$. Test-retest reliability was $r(n$ $=74)=.51, p<.001$.

[Table 1 near here]

\section{Results}

Predicting Perceived Online Safety and Attitudes Towards e-safety Education from

\section{Subjective and Objective Knowledge of Online Safety/Dangers}

To examine research questions 1, 2, and 3, Zero-order Pearson correlations between the study variables are reported in Table 2. Subjective knowledge of online safety/dangers was significantly, albeit modestly, correlated with both perceived online safety $(r=.24, p<.001)$ and objective knowledge of online safety/dangers $(r=.20, p<.001)$. Sex was significantly correlated with both perceived online safety and subjective knowledge of online safety/dangers. Also, age was significantly correlated with perceived online safety, subjective and objective knowledge of online safety/dangers. These significant sex and age differences 
justify testing these as possible moderator variables in the regression models reported next, to examine research question 4.

A hierarchical multiple regression model was run to test if subjective and objective knowledge of online safety/dangers could predict perceived online safety, and also if sex and/or age acted as a moderator. Table 3 provides a summary of the analysis. Sex and age were entered as control variables at step 1 and also to allow their product terms to be entered later in the model. Sex and age significantly predicted perceived online safety such that males and older participants had higher levels of perceived online safety. At step 2 subjective and objective knowledge of online safety/dangers were entered together. At step 3, each product terms were entered separately. The model after step 2 was significant $(p<.001)$. While subjective knowledge was a significant unique predictor of perceived online safety $(p<.001)$, objective knowledge was not $(p>.05)$. The model after step 3 was not significant and none of the four product terms was a significant predictor $(p>.05)$.

A similar hierarchical multiple regression model was run in which attitudes towards esafety served as the dependent variable and the same predictors were entered in the same order. Table 4 provides a summary of the analysis. The model after step 2 was marginally significant $(p$ <.06). This warranted an examination of unique effects. While objective knowledge was a significant unique predictor $(p=.02)$ of attitudes towards e-safety, subjective knowledge was not $(p>.05)$. The model after step 3 was not significant and none of the four product terms were significant predictors of e-safety $(p>.05)$.

[Table 2, 3 \& 4 near here]

\section{Levels of Perceived Online Safety, Subjective and Objective Knowledge of Online} Safety/Dangers, Attitudes towards e-safety Education, and Tests of Sex and Age

\section{Differences}




\section{CHILDREN'S KNOWLEDGE OF ONLINE SAFETY/DANGER}

A series of $t$ tests were conducted to explore sex and age differences in the variables and test research question 4. For the purpose of these analyses, the term younger children relates to those children in year 4 and the term older children relates to those children in year 6 . Girls $(M=2.82, S D=.58)$ felt significantly less safe than boys $(M=3.09, S D=.63), t(319)=$ $3.88, p<.001$, but the Cohen's d effect size of .42 was less than the value of .5 described elsewhere as moderate (Cohen, 1988). Younger children $(M=2.85, S D=.66)$ felt significantly less safe than older children $(M=3.07, S D=.55), t(319)=3.15, p=.002$, with a .37 effect size. On subjective knowledge of online safety/dangers, overall scores were high and did not differ between girls and boys, $t(326)=1.61$. Older children $(M=3.59, S D=.57)$ had significantly higher subjective knowledge scores than younger children $(M=3.30, S D$ $=.78), t(326)=3.79, p<.001$, with a .42 effect size. Boys $(M=1.95, S D=1.08)$ had significantly lower objective knowledge scores than girls $(M=2.47, S D=1.19), t(327)=$ $4.11, \mathrm{p}<.001$, with a moderate effect size of .5 . Younger children $(M=2.03, S D=1.03)$ also had significantly lower objective knowledge scores than older children $(M=2.42, S D=$ $1.17), t(326)=3.09, p=.002$, with a .35 effect size. Overall, participants expressed strong positive attitudes towards e-safety education, with no significant sex difference, $t(317)=$ 1.52 , or age difference $t(317)=1.60$, evident.

In summary, subjective knowledge of online safety/dangers significantly predicted perceived online safety. Girls and younger children also reported feeling less safe online than boys and older children. Younger children also had lower objective and subjective knowledge of online safety/dangers than older children and boys had lower objective knowledge than girls. 


\section{Discussion}

This study contributes to the literature in several novel ways. It has shown that what children think they know about online dangers/how to stay safe online corresponds only weakly with what they can actually articulate about these things. Moreover, while the overall level of subjective knowledge of these issues was high (3.44 on a 1-4 scale), participants could only articulate on average about two distinct responses to suggest they actually had that knowledge. These results suggest a degree of complacency that might leave some young people vulnerable online and make risks more likely to lead to harm for them.

While these findings support the notion that children have some knowledge of online dangers/safety (Betts \& Spenser, 2017; Bond, 2013), they also illustrate that children's objective knowledge of these issues are limited (Livingstone, Haddon et al., 2014). Some of the findings could be interpreted as suggesting that boys may be even more complacent than girls in this regard because while boys had significantly lower objective knowledge of online safety/dangers than girls, they also felt significantly safer than girls. As boys take more risks online (Baumgartner, Valkenburg, \& Peter, 2010; Oksanen et al., 2016; Sasson \& Mesch, 2014), this may make them feel safer in this regard, compared to girls who are exposed to fewer online dangers (Livingstone \& Helsper, 2007). The findings suggest that adults who work directly with young people could usefully 'test' for such a mismatch between subjective and objective levels of e-safety knowledge (especially in boys). If it exists, as it did among the current sample of children, they might consider pointing this out to young people as a way of motivating them to gain a more objective understanding of online risks and how to avoid them. Further, any attempts to gauge how much young people have actually learnt about e-safety from lessons, or to find out what they need to know as lessons are being prepared for them, should make sure they include at least some objective measures (i.e., open questions). Indeed, children's online behaviour has become 'normalised' and part of 
everyday life due to the increased use and expectation by society to be digital literate. This normalisation of using digital technology could make children less aware of online dangers/safety as they are less cautious, which could make young people more vulnerable online (Annansingh \& Veli, 2016). As noted in the Introduction, young children are less exposed to online risks compared to older children, and so it is possible their knowledge of online dangers/safety would differ. The current study found that younger children do show a lower level of objective knowledge compared to their older peers. On the one hand, this could suggest as younger children are less exposed to these risks, their awareness of such dangers is likely to be lower. On the other hand, this could suggest a need for adults who work directly with younger children to make them more aware of these risks, so they are more likely to remain safe online. While the effect sizes for these findings are small, they do provide an initial insight for a currently under-researched population, and as such provides rationale for additional research with younger children.

Overall levels of perceived online safety were fairly high. This is encouraging, given that such feelings would tend to allow young people to get the maximum enjoyment and learning from being online (Finkelhor, 2014; Madden et al., 2013). However, it is important that such feelings of safety are grounded in a good understanding among children. While both subjective and objective e-safety knowledge together significantly predicted perceived safety, it was only subjective knowledge that did so uniquely (i.e., after controlling the variance it shared with objective knowledge). Again, this might suggest that some young people are complacent, i.e., 'I think I know about online dangers and how to avoid them, and so I can feel safe online'. The more desirable situation (i.e., 'I do know about online dangers and how to avoid them, and so I can feel safe online') was not apparent in present study and suggests e-safety educators should strive to promote more objective knowledge of online dangers and how to stay safe while using the internet. It is worrying that the participants could articulate 
so few unsolicited responses to indicate that they actually had a good knowledge of online risks and how to avoid them, on average only two. This suggests that young people could benefit from being helped to develop a broader level of understanding. With this in mind, it was encouraging that, overall, participants expressed strong positive attitudes towards formal e-safety education, as this implies that children would be open to it. Additionally, it was also found via the regression analyses that the more children could articulate online dangers and how to avoid them (objective knowledge) the more favourably inclined they were towards esafety education. The latter result is important because it suggests that if we can help children appreciate some of the dangers associated with being online they will be motivated to find out even more. The issue of children's openness to e-safety education is not trivial, given the research on social validity which has found that children's unfavourable attitudes towards attempts to help them can seriously compromise how much they actually learn (Cowan \& Sheridan, 2003; Witt \& Elliott, 1985). The finding that neither subjective nor objective esafety knowledge predicted attitudes towards formal e-safety education suggests that the former is a poor indicator of who would/would not receive such lessons favorably. Put another way, even if a child already felt that they knew how to stay safe online, and/or actually understood how to stay safe, they might be as open to formal e-safety education as another child who did not feel safe and/or who lacked objective knowledge.

The measure of objective knowledge is made up of two components, namely (i) knowledge about online risks per se and (ii) knowledge of how to stay safe in the face of those risks. It is possible, perhaps even likely, that some children may have good awareness of online risks but be unsure how to stay safe. This issue has some important implications. It suggests future studies would do well to have separate measures of these two aspects of objective knowledge. This would, for instance allow tests of which of them was the better predictor of feeling (un)safe online. Another implication is that e-safety educators would 
need to ensure that both aspects of objective knowledge were addressed in the curricula they deliver.

Limitations of this study need to be noted. The sample, while not small, was drawn from only five schools in the UK and so cannot be considered representative. Hence, the extent to which the findings can be generalised is yet to be established. It should be noted the schools were recruited on a convenience basis, so future research should seek to replicate the findings with a wider sample and using a longitudinal design. However, as outlined in the 'Participants and Procedure' section, steps were taken in the recruitment phase in order to reduce bias and be as representative as possible (Banerjee \& Chaudhury, 2010). Regarding the analytical approach, multi-level modelling was not employed as the sample size in the current study is not large enough for each group (Snijders, 2005). Specifically, as the size of the groups were small, this would increase the risk of biased estimates (Kerkhoff \& Nussbeck, 2019; Maas \& Hox, 2005; Theall et al., 2011), so hierarchal multiple regression was employed. The data was also nested so the type 1 error rate is potentially higher (Aarts et al., 2014). As such, future work in this area should aim to achieve a larger sample in each group to ultise sophisticated approaches (e.g., multi-level modelling). The measures were also restricted to scales with relatively few items, but in their favour, they did yield acceptably reliable data. While the current study highlighted the importance of age and sex differences in 'objective/subjective' knowledge of online dangers/safety, ethnicity data were not collected at the request of the schools and so future research should aim to compare ethnic and cultural differences to help us better understand children's online safety. Future research should consider exploring additional individual characteristic variables such as behavioural attributes and temperament and social-situational factors such as peers to fully test the variables proposed in Morrongiello and Lasenby-Lessard's (2007) model of risk taking. The current study was unable to control for any additional variables in the initial 
collection of data. As such, this does raise an important consideration for future work in this area to fully explore additional variables that may explain alternative explanations for the findings in the current study. However, the current study controlled for age and biological sex, which still offers important implications on a practical level. For example, as the current study found that boys and younger children were poorer at articulating dangers online and how they could personally elude them (objective knowledge), teachers and parents can focus on promoting children's internalised knowledge, especially amongst boys and younger children, of online safety/dangers. An effective strategy to promote this can be implemented through a formal classroom presentation addressing online risks. Children who received this intervention had a higher level of awareness of online risks and strategies to stay safe online, directly after the intervention, and 4 months later (Schilder, Brusselaers, \& Bogaerts, 2016). Schools could also encourage older children to teach younger children about such online safety issues, which is found to be effective for both the tutor and tutee group when testing their knowledge after the intervention (Boulton et al., 2016). In addition, despite missing additional control variables, the current findings offer a unique and important contribution to the literature on children's online safety, specifically addressing the concept of subjective versus objective knowledge, that has not been tested to date in this context.

Finally, the cross-sectional design of the current study makes it difficult to make any causal conclusion. As the data are correlational, the direction of the concluded relationships could have potential reverse effects, which could have implications on strategies to promote knowledge of online safety/dangers. However, as outlined in the Introduction, prior research and theory provided a strong justification to expect the direction examined and found in the current study. It is important to acknowledge these limitations when reflecting on the overall conclusions and findings. Despite this, the current study offers a unique contribution to the 
literature examining perceived online safety, subjective and objective knowledge of online safety/dangers, and attitudes to e-safety education.

Future research should more closely address the views of children through qualitative or mixed-method approaches to provide a narrative of depth and insight on children's online activity, particularly addressing their emotions when they come into contact with online dangers, which was not addressed in the current study. In addition, the study did not measure other important roles when predicting perceived online safety. For example, future research can build on the current findings by exploring the roles of time spent online, number of devices connected to the internet and network size on children's perceived online safety.

In conclusion, the participants overall, especially boys and older children, felt rather safe online and this might help them gain maximum enjoyment and learning. They also perceived that they were well-versed in online dangers and how to avoid them, but such subjective knowledge had only moderate correspondence with a more objective measure. The latter indicated that many participants, especially boys and younger children, were poor at articulating online risks and strategies for staying safe. Moreover, it was only subjective knowledge, and not objective knowledge, that predicted perceived safety online. This suggests that some, perhaps many, young people are complacent in that their feelings of being safe are based on a possibly mistaken belief that they are 'online savvy'. We suggest that more should be done to enable children to continue to feel safe online but on the basis of stronger, internalised knowledge of some key dangers and how to avoid them. The finding that participants had favourable attitudes towards e-safety education suggests the latter has an important role to play in achieving this goal. It is recommended schools ensure all teachers are trained and equipped with the relevant e-safety resources in order to build children's digital literacy and awareness to help them be safer online. As a suggestion for further work, and to help children feel safer online, society needs to be educated on strategies to promote 
CHILDREN'S KNOWLEDGE OF ONLINE SAFETY/DANGER

children's development, and to position more importance to the voices of children (YoungBruehl, 2012). 
CHILDREN'S KNOWLEDGE OF ONLINE SAFETY/DANGER

\section{Footnote}

${ }^{1}$ Note for the purpose of the results younger children are those in school year 4 (typically aged 8-9) and older children are those in school year 6 (typically aged 10-11).

\section{Author Disclosure Statement}

No competing financial interests exist. 


\section{References}

Aarts, E., Verhage, M., Veenvliet, J. V., Dolan, C. V., \& van der Sluis, S. (2014). A solution to dependency: Using multilevel analysis to accommodate nested data. Nature Neuroscience, 17, 491-496.

Annansingh, F., \& Veli, T. (2016). An investigation into risks awareness and e-safety needs of children on the internet: a study of Devon, UK. Interactive Technology and Smart Education, 13(2), 147-165.

Banerjee, A., \& Chaudhury, S. (2010). Statistics without tears: Populations and samples. Industrial psychiatry journal, 19(1), 60.

Baumgartner, S. E., Valkenburg, P. M., \& Peter, J. (2010). Unwanted online sexual solicitation and risky sexual online behavior across the lifespan. Journal of Applied Developmental Psychology, 31(6), 439-447.

Berchtold, A. (2016). Test-retest: Agreement or reliability? Methodological Innovations. doi.org/10.1177/2059799116672875

Betts, L. R., \& Spenser, K. A. (2017). “People think it's a harmless joke”: young people's understanding of the impact of technology, digital vulnerability and cyberbullying in the United Kingdom. Journal of Children and Media, 11(1), 20-35.

Bond, E. (2013). Mobile phones, risk and responsibility: Understanding children's perceptions. Cyberpsychology: Journal of Psychosocial Research on Cyberspace, $7(1)$.

Borgers, N., De Leeuw, E., \& Hox, J. (2000). Children as respondents in survey research: Cognitive development and response quality 1. Bulletin of Sociological Methodology/Bulletin de méthodologie sociologique, 66(1), 60-75.

Boulton, M. J., Boulton, L., Camerone, E., Down, J., Hughes, J., Kirkbride, C., ... \& Sanders, 
J. (2016). Enhancing primary school children's knowledge of online safety and risks with the CATZ Cooperative Cross-Age Teaching Intervention: results from a pilot study. Cyberpsychology, Behavior, and Social Networking, 19(10), 609-614.

Boulton, M. J., Duke, E., Holman, G., Laxton, E., Nicholas, B., Spells, R., ... \& Woodmansey, H. (2009). Associations between being bullied, perceptions of safety in classroom and playground, and relationship with teacher among primary school pupils. Educational Studies, 35(3), 255-267.

Boulton, M., Woodmansey, H., Williams, E., Spells, R., Nicholas, B., Laxton, E., ... \& Duke, E. (2012). Associations between peer bullying and classroom concentration: evidence for mediation by perceived personal safety and relationship with teacher. Educational Psychology, 32(3), 277-294.

Brucks, M. (1985). The effects of product class knowledge on information search behavior. Journal of Consumer Research, 13, 58-63

Chaudron, S., Beutel, M. E., Černikova, M., Donoso Navarette, V., Dreier, M., Fletcher Watson, B.,... Wölfling, K. (2015). Young children (0-8) and digital technology: A qualitative exploratory study across seven countries. Retrieved from http://publications.jrc.ec.europa.eu/repository/handle/JRC93239

Cohen J. (1988). Statistical Power Analysis for the Behavioral Sciences. New York, NY: Routledge Academic

Cowan, R. J., \& Sheridan, S. M. (2003). Investigating the acceptability of behavioral interventions in applied conjoint behavioral consultation: Moving from analog conditions to naturalistic settings. School Psychology Quarterly, 18(1), 1.

Creswell, J. W., \& Poth, C. N. (2016). Qualitative inquiry and research design: Choosing among five approaches. Sage publications.

Dallago, L., Perkins, D. D., Santinello, M., Boyce, W., Molcho, M., \& Morgan, A. (2009). 
Adolescent place attachment, social capital, and perceived safety: A comparison of 13 countries. American journal of community psychology, 44(1-2), 148-160.

Delfabbro, P., Lahn, J., \& Grabosky, P. (2006). It's not what you know, but how you use it: Statistical knowledge and adolescent problem gambling. Journal of Gambling Studies, 22(2), 179-193.

Donoso, V., Ólafsson, K., \& Broddason, T. (2009). What we know, what we do not know. In: S. Livingstone \& L. Haddon (Eds.), Kids Online: Opportunities and risks for children (pp. 19-30). Bristol: The Policy Press.

Finkelhor, D. (2014). Commentary: Cause for alarm? Youth and internet risk research-a commentary on Livingstone and Smith (2014). Journal of child psychology and psychiatry, 55(6), 655-658.

Fogel, J., \& Nehmad, E. (2009). Internet social network communities: Risk taking, trust, and privacy concerns. Computers in human behavior, 25(1), 153-160.

Gawronski, B., \& Bodenhausen, G. V. (2011). The associative-propositional evaluation model: Theory, evidence, and open questions. Advances in Experimental Social Psychology, 44, 59-127. doi: 10.1016/B978-0-12-385522-0.00002-0

Görzig, A. (2012). Methodological framework: the EU Kids Online project. Children, risk and safety online: Research and policy challenges in comparative perspective, 15-32.

Gustafson, P. E. (1998). Gender differences in risk perception: Theoretical and methodological perspectives. Risk Analysis, 18(6), 805-811.

Gwet, K. L. (2014). Handbook of inter-rater reliability: The definitive guide to measuring the extent of agreement among raters. Advanced Analytics, LLC.

Han,T-I. (2019). Objective knowledge, subjective knowledge, and prior experience of organic cotton apparel. Fashion and Textiles, 6, 4. https://doi.org/10.1186/s40691$\underline{018-0168-7}$ 
Hayes, A. F., \& Krippendorff, K. (2007). Answering the call for a standard reliability measure for coding data. Communication methods and measures, 1(1), 77-89.

Helsper, E. J., \& Eynon, R. (2010). Digital natives: where is the evidence?. British educational research journal, 36(3), 503-520.

Helsper, E, J., \& Eynon, R. (2013). Distinct skill pathways to digital engagement. European Journal of Communication, 28(6), 696-671.

Hinkle, J. C. (2015). Emotional fear of crime vs. perceived safety and risk: Implications for measuring "fear" and testing the broken windows thesis. American Journal of Criminal Justice, 40(1), 147-168.

Holloway, D., Green, L., \& Livingstone, S. (2013). Zero to eight: Young children and their internet use. London: EU Kids Online, LSE

Ivcevic, Z., \& Ambady, N. (2013). Face to (Face)book: The two faces of social behavior, Journal of Personality, 81(3), 290-301.

Junger-Tas, J., Ribeaud, D., \& Cruyff, M. J. (2004). Juvenile delinquency and gender. European Journal of Criminology, 1(3), 333-375.

Kerkhoff, D., \& Nussbeck, F. W. (2019). The influence of sample size on parameter estimates in three-level random-effects models. Frontiers in psychology, 10.

Kouta, C., \& Tolma, E. L. (2008). Sexuality, sexual and reproductive health : An exploration of the knowledge, attitudes and beliefs of the Greek-Gypriot adolescents. IJHPEPromotion \& Education, 15(4), 24-31.

Krippendorff, K. (2004). Reliability in content analysis. Human communication research, 30(3), 411-433

Lavrakas, P. J. (2008). Encyclopedia of survey research methods. Sage Publications. 
Lbrahim, G. (1995). Knowledge, attitude and practice the three pillars of excellence and wisdom: A place in the medial profession. Eastern Mediterranean health Journal, l(1), 8-16.

Lee, S. J., \& Chae, Y. G. (2012). Balancing participation and risks in children's internet use: The role of internet literacy and parental mediation. Cyberpsychology, Behavior, and Social Networking, 15(5), 257-262.

Lenske, G., \& Helmke, A. (2015). Child Respondents—Do They Really Answer What Scientific Questionnaires Ask For?. In Multidisciplinary research on teaching and learning (pp. 146-166). Palgrave Macmillan, London.

Leung, L., \& Lee, P. S. (2012). The influences of information literacy, internet addiction and parenting styles on internet risks. New Media \& Society, 14(1), 117-136.

Livingstone, S. (2013). Online risk, harm and vulnerability: Reflections on the evidence base for child Internet safety policy. ZER: Journal of Communication Studies, 18(35), 1328.

Livingstone, S., Davidson, J., Bryce, J., Batool, S., Haughton, C., \& Nandi, A. (2017). Children's online activities, risks and safety: a literature review by the UKCCIS evidence group.

Livingstone, S., Haddon, L., Görzig, A., \& Ólafsson, K. (2011). Risks and safety on the internet: the perspective of European children: full findings and policy implications from the EU Kids Online survey of 9-16 year olds and their parents in 25 countries.

Livingstone, S., Haddon, L., Vincent, J., Mascheroni, G., \& Ólafsson, K. (2014). Net children go mobile: The UK report. London: London School of Economics and Political Science.

Livingstone, S., \& Helsper, E. J. (2007). Taking risks when communicating on the Internet: 
The role of offline social-psychological factors in young people's vulnerability to online risks. Information, Communication \& Society, 10(5), 619-644.

Livingstone, S., Kirwil, L., Ponte, C., \& Staksrud, E. (2014). In their own words: What bothers children online?. European Journal of Communication, 29(3), 271-288.

Livingstone, S., Ólafsson, K., Helsper, E. J., Lupiáñez-Villanueva, F., Veltri, G. A., \& Folkvord, F. (2017). Maximising opportunities and minimizing risks for children online: The role of digital skills in emerging strategies of parental mediation. Journal of Communication, 67, 82-105.

Livingstone, S., \& Smith, P. K. (2014). Annual research review: Harms experienced by child users of online and mobile technologies: The nature, prevalence and management of sexual and aggressive risks in the digital age. Journal of child psychology and psychiatry, 55(6), 635-654.

Maas, C. J., \& Hox, J. J. (2005). Sufficient sample sizes for multilevel modeling. Methodology, 1(3), 86-92

Macaulay, P. J., Boulton, M. J., \& Betts, L. R. (2019). Comparing early adolescents' positive bystander responses to cyberbullying and traditional bullying: the impact of severity and gender. Journal of Technology in Behavioral Science, 4(3), 253-261.

Madden, M., Lenhart, A., Duggan, M., Cortesi, S., \& Gasser, U. (2013). Teens and technology 2013 (pp. 1-19). Washington, DC: Pew Internet \& American Life Project. Morrongiello, B. A., Cusimano, M., Barton, B. K., Orr, E., Chipman, M., Tyberg, J. ... Bekele, T. (2010). Development of the BACKIE questionnaire: A measure of children's behaviors, attitudes, cognitions, knowledge, and injury experiences. Accident Analysis and Prevention, 42, 75-83. doi:10.1016/j.aap.2009.07.006

Morrongiello, B. A., Cusimano, M., Orr, E., Barton, B., Chipman, M., Tyberg, J. ... Bekele, T. (2008). School-age children's safety attitudes, cognitions, knowledge, and injury 
experiences: How do these relates to their safety practices? Injury Prevention, 14, 176-179. doi: 10.1136/ip.2007.016782

Morrongiello, B., \& Lasenby-Lessard, J. (2007). Psychological determinants of risk taking by children: An integrative model and implications for interventions. Injury Prevention, 13, 20-25. doi: 10.1136/ip.2005.011296

Morrongiello, B. A., McArthur, B., Kane, A., \& Fleury, R. (2013). Only kids who are fools would do that!: Peer social norms influence children's risk-taking decisions. Journal of Pediatric Psychology, 38, 744-755. doi: 10.1093/jpepsy/jst019

Ofcom (2017). Children and parents: Media use and attitudes report. London: Office of Communications.

Oksanen, A., Näsi, M., Minkkinen, J., Keipi, T., Kaakinen, M., \& Räsänen, P. (2016). Young people who access harm-advocating online content: A four-country survey. Cyberpsychology: Journal of Psychosocial Research on Cyberspace, 10(2).

Ponte, C., Simões, J. A., \& Jorge, A. (2013). Do questions matter on children's answers about internet risk and safety?. Cyberpsychology: Journal of Psychosocial Research on Cyberspace, $7(1)$.

Riley, A. W. (2004). Evidence that school-age children can self-report on their health. Ambulatory Pediatrics, 4(4), 371-376.

Saldaña, J. (2015). The coding manual for qualitative researchers. Sage.

Sasson, H., \& Mesch, G. (2014). Parental mediation, peer norms and risky online behavior among adolescents. Computers in Human Behavior, 33, 32-38.

Schilder, J. D., Brusselaers, M. B., \& Bogaerts, S. (2016). The effectiveness of an intervention to promote awareness and reduce online risk behavior in early adolescence. Journal of youth and adolescence, 45(2), 286-300

Sharples, M., Graber, R., Harrison, C., \& Logan, K. (2009). E-safety and Web 2.0 for 
children aged 11-16. Journal of Computer Assisted Learning, 25(1), 70-84.

Shoukri, N. M., Asyali, M. H., \& Donner, A. (2004). Sample size requirements and the design of reliability study: Review and new results. Statistical Methods in Medical Research, 13, 251-271. doi: 10.1191/0962280204sm365ra

Snijders, T. A. B. (2005). Power and sample size in multilevel modeling. In B. S. Everitt \& D. C. Howell (Eds.), Encyclopedia of statistics in behavioral science (Vol. 3, pp. 1570-1573). Chichester: Wiley.

Stamoulis, K., \& Farley, F. (2010). Conceptual approaches to adolescent online risktaking. Cyberpsychology: Journal of Psychosocial Research on Cyberspace, 4(1).

Streiner, D. L. (2003). Starting at the beginning: an introduction to coefficient alpha and internal consistency. Journal of personality assessment, 80(1), 99-103.

Theall, K. P., Scribner, R., Broyles, S., Yu, Q., Chotalia, J., Simonsen, N., ... \& Carlin, B. P. (2011). Impact of small group size on neighbourhood influences in multilevel models. Journal of Epidemiology \& Community Health, 65(8), 688-695.

Tieskens, J. M., Buil, M., Koot, S., Krabbendam, L., \& van Lier, P. A. C. (2018). Elementary school children's associations of antisocial behaviour with risk-taking across 7-11 years. The Journal of Child Psychology and Psychiatry, 59, 1052-1060. doi:10.1111/jcpp.12943

Thorton, S. (2008). Understanding human development: biological, social and psychological processes from conception to adult life. New York: Palgrave Macmillian van den Bos, W., \& Hertwig, R. (2017). Adolescents display distinctive tolerance to ambiguity and to uncertainty during risky decision making. Scientific Reports 7: 40962 (2017) 
CHILDREN'S KNOWLEDGE OF ONLINE SAFETY/DANGER

Wanous, J. P., Reichers, A. E., \& Hudy, M. J. (1997). Overall job satisfaction: How good are single-item measures? Journal of Applied Psychology, 82, 247-252. doi: 002190HV97/S3.00

Waterman, A. H., Blades, M., \& Spencer, C. (2000). Do children try to answer nonsensical questions?. British Journal of Developmental Psychology, 18(2), 211-225.

Witt, J. C., \& Elliott, N. S. (1985). Effectiveness of classroom management strategies. Advances in school psychology, 4, 251-288.

Young-Bruehl, E. (2012). Childism: Confronting prejudice against children. Yale University Press 
Table 1: Information used to code 'objective knowledge' of online dangers/safety

\begin{tabular}{cc}
\hline Themes & Examples of responses \\
\hline 1. People online pretending to be somebody else & 'People we talk to online may not \\
& be who they say they are'
\end{tabular}

Identifies the risk of meeting people online who are impersonating other's identity or interacting online in a manner that does not reflect their actual identity.

2. Being in contact with people we do not know

Responses where the child recognises risks interacting with people they do not know. Identifies that meeting strangers online can be dangerous, especially if they ask to meet face-to-face.

\section{Sharing personal information/personal photographs or videos}

Responses identify the need to keep personal information and materials private. The child recognises that some people online will ask for personal information including name, address, location and personal materials including photos and videos.

\section{Cyberbullying}

Children recognise the risk of being cyberbullied online. Aware that some people online may intentionally target others in a hurtful manner.
'Some people online may pretend to be somebody else'

'If you feel someone online is pretending to be somebody else, tell a teacher or adult'

'Talking to people online we haven't met in person can be dangerous'

'People we talk to online can be strangers, and may ask to meet in person or want personal information'

'Never meet anybody online we do not know, unless discussed with a parent or teacher'

'Sharing information online about my name and family could be dangerous'

'If I share photos online, everybody will be able to see them'

'Do not send any personal information to people online if we do not know who they are'

'You may receive nasty messages from someone you don't know every day' 
5. Inappropriate and/or distressing content

Identifies online dangers of inappropriate or distressing nature including violent media, pornography and distressing written content.

\section{Computer viruses}

Awareness of online content that can damage digital technology devices and/or used to compromise personal information like passwords.
'People online can say nasty things to other people, so everybody can see'

'If you receive a nasty comment, block the person and tell an adult straight away'

'Some online pages may have violent videos that can be upsetting'

'Online forums can have aggressive comments'

'If you see something that makes you upset, tell a teacher or adult'

'Some links may take you to an unknown page and damage your laptop'

'Attachments and adverts online may have a virus to damage your device'

'Never open a link sent to you, unless you know the person or have spoken to a teacher or adult' 
CHILDREN'S KNOWLEDGE OF ONLINE SAFETY/DANGER

Table 2: Zero-order Correlations Among the Study Variables

\begin{tabular}{lccccc}
\hline & 2 & 3 & 4 & 5 & 6 \\
\hline Perceived online safety (1) & $.24^{* *}$ & .07 & -.11 & $.21^{* *}$ & $.17^{* *}$ \\
Subjective knowledge of online safety/dangers (2) & & $.20^{* *}$ & -.01 & .09 & $.21^{* *}$ \\
Objective knowledge of online safety/dangers (3) & & $.13^{*}$ & $-.22^{* *}$ & $.17^{* *}$ \\
Attitudes to e-safety education (4) & & & -.09 & -.09 \\
Sex (5) & & & & \\
Age (6) & & & & \\
\hline
\end{tabular}

Note. Variables were measured on a 1-4 scale, except objective knowledge of online safety/dangers which was measured on a ratio scale as a true score from zero. $* \mathrm{p}<.05 . * * \mathrm{p}<.001$. 


\section{CHILDREN'S KNOWLEDGE OF ONLINE SAFETY/DANGER}

Table 3: Summary of Hierarchical Regression Analysis for Variables Predicting Perceived Online Safety

\begin{tabular}{|c|c|c|c|c|c|c|c|c|c|c|c|c|}
\hline \multirow[b]{2}{*}{ Variable } & \multicolumn{4}{|c|}{ Model 1} & \multicolumn{4}{|c|}{ Model 2} & \multicolumn{4}{|c|}{ Model 3} \\
\hline & $B$ & $S E B$ & $\beta$ & & $B$ & $S E B$ & $\beta$ & & $B$ & $S E B$ & $\beta$ & \\
\hline Sex & .25 & .07 & $.21 * * *$ & & .25 & .07 & $.20 * * *$ & & .20 & .33 & .16 & \\
\hline Age & .21 & .07 & $.17 * *$ & & .15 & .07 & $.12 *$ & & .15 & .07 & .12 & \\
\hline $\begin{array}{l}\text { Subjective knowledge of } \\
\text { online safety/dangers }\end{array}$ & & & & & .16 & .05 & $.19 * * *$ & & .16 & .06 & $.18^{*}$ & \\
\hline $\begin{array}{l}\text { Objective knowledge of } \\
\text { online safety/dangers }\end{array}$ & & & & & .03 & .03 & .05 & & .03 & .03 & .05 & \\
\hline Sex X subjective knowledge & & & & & & & & & .01 & .10 & .04 & \\
\hline Sex X objective knowledge & & & & & & & & & & & & \\
\hline Age $X$ subjective knowledge & & & & & & & & & & & & \\
\hline Age $X$ objective knowledge & & & & & & & & & & & & \\
\hline $\mathrm{R}^{2}$ & & & & .07 & & & & .11 & & & & .11 \\
\hline$\Delta \mathrm{R}^{2}$ & & & & & & & & $.04 * * *$ & & & & .00 \\
\hline
\end{tabular}


CHILDREN'S KNOWLEDGE OF ONLINE SAFETY/DANGER

Table 3 Continued ...

\begin{tabular}{|c|c|c|c|c|c|c|c|c|c|c|c|c|}
\hline \multirow[b]{2}{*}{ Variable } & \multicolumn{4}{|c|}{ Model 4} & \multicolumn{4}{|c|}{ Model 5} & \multicolumn{4}{|c|}{ Model 6} \\
\hline & $B$ & $S E B$ & $\beta$ & & $B$ & $S E B$ & $\beta$ & & $B$ & $S E B$ & $\beta$ & \\
\hline Sex & .19 & .14 & .15 & & .25 & .07 & $.20 * * *$ & & .25 & .07 & $.20 * * *$ & \\
\hline Age & .15 & .07 & $.12 *$ & & .10 & .36 & .08 & & .16 & .15 & .13 & \\
\hline $\begin{array}{l}\text { Subjective knowledge of } \\
\text { online safety/dangers }\end{array}$ & .16 & .05 & $.19 * * *$ & & .16 & .06 & $.18 * *$ & & .16 & .05 & $.19 * * *$ & \\
\hline $\begin{array}{l}\text { Objective knowledge of } \\
\text { online safety/dangers }\end{array}$ & .02 & .04 & .03 & & .03 & .03 & .05 & & .03 & .04 & .06 & \\
\hline Sex X subjective knowledge & & & & & & & & & & & & \\
\hline Sex X objective knowledge & .03 & .06 & .07 & & & & & & & & & \\
\hline Age $\mathrm{X}$ subjective knowledge & & & & & .02 & .10 & .04 & & & & & \\
\hline Age $\mathrm{X}$ objective knowledge & & & & & & & & & -.00 & .06 & -.01 & \\
\hline $\mathrm{R}^{2}$ & & & & .11 & & & & .11 & & & & .11 \\
\hline$\Delta \mathrm{R}^{2}$ & & & & .00 & & & & .00 & & & & .00 \\
\hline
\end{tabular}

Note: $* p<.05 . * * p<.01 . * * * p<.001$. 


\section{CHILDREN'S KNOWLEDGE OF ONLINE SAFETY/DANGER}

Table 4: Summary of Hierarchical Regression Analysis for Variables Predicting Attitudes Towards E-Safety

\begin{tabular}{|c|c|c|c|c|c|c|c|c|c|c|c|c|}
\hline \multirow[b]{2}{*}{ Variable } & \multicolumn{4}{|c|}{ Model 1} & \multicolumn{4}{|c|}{ Model 2} & \multicolumn{4}{|c|}{ Model 3} \\
\hline & $B$ & $S E B$ & $\beta$ & & $B$ & $S E B$ & $\beta$ & & $B$ & $S E B$ & $\beta$ & \\
\hline Sex & -.08 & .50 & -.09 & & -.05 & .05 & -.05 & & -.12 & .26 & -.13 & \\
\hline Age & -.08 & .50 & -.09 & & -.10 & .05 & -.11 & & -.10 & .05 & -.11 & \\
\hline $\begin{array}{l}\text { Subjective knowledge of } \\
\text { online safety/dangers }\end{array}$ & & & & & -.01 & .04 & -.01 & & -.02 & .05 & -.02 & \\
\hline $\begin{array}{l}\text { Objective knowledge of } \\
\text { online safety/dangers }\end{array}$ & & & & & .05 & .02 & $.14 *$ & & .05 & .02 & $.14^{*}$ & \\
\hline Sex X subjective knowledge & & & & & & & & & .02 & .07 & .09 & \\
\hline Sex X objective knowledge & & & & & & & & & & & & \\
\hline Age X subjective knowledge & & & & & & & & & & & & \\
\hline Age $X$ objective knowledge & & & & & & & & & & & & \\
\hline $\mathrm{R}^{2}$ & & & & .02 & & & & .03 & & & & .03 \\
\hline$\Delta \mathrm{R}^{2}$ & & & & & & & & .02 & & & & .00 \\
\hline
\end{tabular}


CHILDREN'S KNOWLEDGE OF ONLINE SAFETY/DANGER

Table 4 Continued ...

\begin{tabular}{|c|c|c|c|c|c|c|c|c|c|c|c|c|}
\hline \multirow[b]{2}{*}{ Variable } & \multicolumn{4}{|c|}{ Model 4} & \multicolumn{4}{|c|}{ Model 5} & \multicolumn{4}{|c|}{ Model 6} \\
\hline & $B$ & $S E B$ & $\beta$ & & $B$ & $S E B$ & $\beta$ & & $B$ & $S E B$ & $\beta$ & \\
\hline Sex & .00 & .11 & .00 & & -.05 & .05 & -.05 & & -.04 & .04 & -.05 & \\
\hline Age & -.10 & .05 & $-.11 *$ & & -.06 & .27 & -.07 & & -.22 & .11 & $-.25^{*}$ & \\
\hline $\begin{array}{l}\text { Subjective knowledge of } \\
\text { online safety/dangers }\end{array}$ & -.01 & .04 & -.01 & & -.00 & .05 & -.01 & & -.00 & .04 & -.01 & \\
\hline $\begin{array}{l}\text { Objective knowledge of } \\
\text { online safety/dangers }\end{array}$ & .06 & .03 & $.17 *$ & & .05 & .02 & $.14 *$ & & .03 & .03 & .07 & \\
\hline Sex X subjective knowledge & & & & & & & & & & & & \\
\hline Sex X objective knowledge & -.02 & .04 & -.06 & & & & & & & & & \\
\hline Age $\mathrm{X}$ subjective knowledge & & & & & -.01 & .08 & -.04 & & & & & \\
\hline Age X objective knowledge & & & & & & & & & .05 & .04 & .17 & \\
\hline $\mathrm{R}^{2}$ & & & & .03 & & & & .03 & & & & .04 \\
\hline$\Delta \mathrm{R}^{2}$ & & & & .00 & & & & .00 & & & & .01 \\
\hline
\end{tabular}

Note: $* p<.05 . * * p<.01 . * * * p<.001$. 